
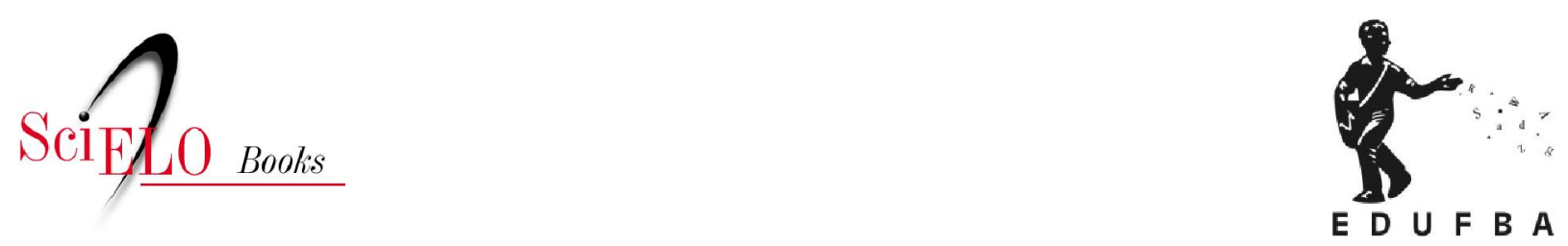

\title{
Evolução do uso da internet na participação política de organizações da sociedade civil
}

\author{
Jussara Borges \\ Othon Jambeiro
}

\section{SciELO Books / SciELO Livros / SciELO Libros}

BORGES, J., and JAMBEIRO, O. Evolução do uso da internet na participação política de organizações da sociedade civil. In: PINHO, J.A.G., ed. Artefatos digitais para mobilização da sociedade civil: perspectivas para avanço da democracia [online]. Salvador: EDUFBA, 2016, pp. 7397. ISBN: 978-85-232-1877-5. https://doi.org/10.7476/9788523218775.0005.

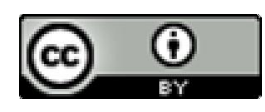

All the contents of this work, except where otherwise noted, is licensed under a Creative Commons Attribution $\underline{4.0 \text { International license. }}$

Todo o conteúdo deste trabalho, exceto quando houver ressalva, é publicado sob a licença Creative Commons Atribição 4.0.

Todo el contenido de esta obra, excepto donde se indique lo contrario, está bajo licencia de la licencia Creative Commons Reconocimento 4.0. 


\section{EVOLUÇÃO DO USO DA INTERNET NA PARTICIPAÇÃO POLÍTICA DE ORGANIZAÇÕES DA SOCIEDADE CIVIL'}

JUSSARA BORGES, OTHON JAMBEIRO

INTRODUÇÃO

Muitos estudos têm se voltado para as possibilidades de uso político da internet. Alguns pesquisadores acreditam inclusive que essa nova tecnologia poderia reviver o sentido político da democracia direta, tornando-se uma ágora digital. Este trabalho, entretanto, segue uma linha de raciocínio diferente: considera os caminhos que a participação política tem trilhado na democracia, levantando as possibilidades que a internet apresenta para a extensão da participação em democracias representativas, mais que sua substituição pelo modelo direto.

Para a observação empírica do uso da internet para ações políticas, foram selecionadas Organizações da Sociedade Civil (OSC). Essas organizações despontaram como atores sociais relevantes para se observar a participação política, porque tanto a evolução democrática no contexto nacional quanto a evolução de suas práticas têm convergido para impul-

I Esta pesquisa recebe apoio financeiro do Conselho Nacional de Pesquisa (CNPq); e é desenvolvida no âmbito do Grupo de Estudos de Políticas de Informação, Comunicações e conhecimento (Gepicc). 
sioná-las a atuar fortemente neste campo. Elas têm se estabelecido socialmente como agentes capazes de revigorar o poder de comunidades, formar cidadãos, fomentar valores de respeito e colaboração, representar interesses de grupos excluídos etc. (MAIA, 2011)

A apropriação da internet por OSC em Salvador vem sendo estudada pelo Gepicc ${ }^{2}$ desde 2010.3 A partir de 2012, novos dados empíricos coletados permitiram traçar a evolução das aplicações dadas às ferramentas digitais para atuação política dessas organizações, ${ }^{4}$ tornando possível um aprofundamento na compreensão do papel que a internet assumiu nas estratégias e nas ações dessas organizações. Este texto dedica-se exatamente a isso.

Organizado em quatro partes principais, o trabalho se exprime teoricamente por meio de uma discussão sobre a relação entre participação política e internet. Este referencial dá embasamento à análise e interpretação dos resultados encontrados em campo. Além dessas duas partes, há uma terceira, onde são explicados os procedimentos metodológicos empregados, e uma quarta e última, conclusiva, na qual as três outras servem de base para a compreensão de como as Tecnologias de Informação e Comunicação (TIC) inserem-se no contexto da atuação política de organizações da sociedade civil no Brasil.

\section{PARTICIPAÇÃO POLÍTICA E INTERNET: ASPECTOS CONCEITUAIS}

A condição básica para a participação cívica e política dos cidadãos é a percepção da existência de problemas e a consciência de que tais problemas podem ser resolvidos mediante determinados tipos de ação. A comunicação, em todas as suas formas - e agora particularmente com a tecnologia da internet - contribui decisivamente nisso com o fornecimento de informações, opiniões e propostas, a respeito dos pro-

2 Grupo de Estudos de Políticas de Informação, Comunicações e Conhecimento, vinculado ao Instituto de Ciência da Informação/UFBA. Ver Gepicc, 2013.

3 Ver, entre outros: Borges $(2011,2012)$, Borges e Jambeiro (2012b) e Jambeiro e Borges (2010).

4 Ver: Borges, Brandão e Martins (2013), Borges, Lessa e Brandão (2013) e Borges; e colaboradores (2013). 
blemas e de suas soluções. Ela permite, pois, o conhecimento do problema e das variadas formas de solucioná-lo, e notadamente contribui para a formação da vontade de mudar.

Assim compreendido, o processo parece ser de natureza individual. Mas, na verdade, tudo isso ocorre mediado por grupos de referência constituídos na sociedade. Estes grupos assumem diversas formas, entre as quais as chamadas Organizações da Sociedade Civil (OSC). São estas que além de servirem de filtro na percepção dos problemas, se constituem também como instrumentos de adoção das soluções e de negociadores destas com outras organizações e, particularmente com o poder político. Elas são um dos caminhos de que o cidadão dispõe para a participação política, sobretudo no que se refere aos benefícios ou malefícios à sua vida cotidiana.

Reunindo pessoas com interesses mais ou menos convergentes, a OSC se constitui em ente jurídico uno, e age como tal. Isto é, agregando variados indivíduos, articula seus interesses e se apresenta à sociedade e ao mundo político como uma unidade. Este trabalho trata destas entidades, que se constituem de indivíduos, assumem posições, perseguem objetivos e desenvolvem estratégias de ação como uma unidade social e política.

Já a associação da Internet como um instrumento de democratização vem da sua capacidade de potencializar o acesso à informação e à comunicação multidirecional, “[...] porque se a informação somente flui em um só sentido, estamos criando e reproduzindo cidadãos passivos que só se contentam em estar informados e não em participar ativamente dos assuntos públicos." (NUNES, 2007, p. 4)

Dahlberg (2001) observou que a emergência da Internet levou três dos principais modelos de democracia a se voltarem para suas potencialidades. O modelo liberal vê a Rede como um meio poderoso para o cidadão ter acesso à informação atualizada e fazer suas escolhas, qualificando assim a competição de interesses. O modelo comunitarista5 assume a Internet como um meio ideal para o diálogo, através do qual se

5 O "modelo comunitarista" de Dahlberg assemelha-se ao "modelo participacionista". 
descobre identidades e propósitos compartilhados, ou seja, o diálogo é desejável para descobrir o bem comum já existente. Em contraste, o modelo deliberativo define o diálogo como um meio através do qual os participantes podem discutir e entender as diferenças, e decidir racionalmente, sendo a internet um precioso instrumento para a realização deste sonho. Gomes (2005a, p. 218), por exemplo, diz que a introdução dessa nova plataforma tecnológica:

[...] faz ressurgir fortemente as esperanças de modelos alternativos de democracia, que implementam uma terceira via entre a democracia representativa, que retira do povo a decisão política, e a democracia direta, que a quer inteiramente consignada ao cidadão. Estes modelos giram ao redor da idéia de democracia participativa e, nos últimos dez anos, na forma da democracia deliberativa, para a qual a Internet é decididamente uma inspiração.

Outros autores apontam caminhos paralelos que a internet pode construir para a consecução desses modelos de democracia. Johnston (2009) aposta na transparência dos processos políticos já existentes como a base para o aumento da participação do cidadão. Chrissafis e Rohen (2009, p. 91, tradução nossa) acreditam que as tecnologias digitais podem simplificar os processos de tomada de decisão e contribuir para tornar mais claros os textos legislativos: "Estas tecnologias podem ajudar a visualizar os argumentos e os impactos das decisões propostas, monitorar os processos de decisão e permitir aos cidadãos descobrir quais decisões estão sendo tomadas e quando é apropriado agir." ${ }^{6}$ Ronca e Costa (2002) afirmam que a Internet - que representa a principal convergência das tecnologias de informação e comunicação (TIC) e organiza-se em formato de rede - se constituirá no próprio espaço comum do conhecimento, onde a construção de saberes é coletiva, a partir de redes de compartilhamento que se organizam em sistemas circulares ou horizontais de transmissão de informações.

\footnotetext{
6 "These technologies can help visualize arguments and impacts of proposed decisions, monitor decision-making processes and enable citizens to find out what decisions are being taken and when it is appropriate to act."
} 
Isso permitiria que a produção de conhecimento e a difusão de informações fossem cada vez mais distribuídas entre os inúmeros agentes através da web, com um potencial de interação inédito se comparado aos meios de comunicação tradicionais. Nessa linha, Santos (2002) diz que grupos excluídos têm se apropriado das tecnologias para estabelecer laços e se fortalecer: "[...] a intensificação exponencial das relações transfronteiriças e as novas tecnologias de informação e comunicação produziram alterações profundas nas escalas espaciais e temporais da ação social."

Ainda no âmbito das relações entre os indivíduos, Bucy e Gregson (2001, p. 365, tradução nossa) apostam na intensificação da comunicação entre cidadãos e políticos:

Ao invés de ser imposto um papel passivo no processo político, o eleitorado é simbólica ou materialmente empoderado através da arquitetura de comunicação em duas vias para interagir diretamente com os candidatos.?

Mas há também os autores que procuram mostrar que estes caminhos abertos pela internet não estão isolados, nem têm autonomia nem potencial para impor-se e moldar esses novos modelos de gestão democrática. Eles chamam a atenção para, por exemplo, a crescente concentração de propriedade dos grandes meios de comunicação comerciais entre conglomerados que dominam não só a mídia tradicional mas também a própria infraestrutura da internet:

A mídia contemporânea está sendo moldada por várias tendências conflitantes e contraditórias: ao mesmo tempo que o ciberespaço substitui algumas informações tradicionais e gatekeepers culturais, há também uma concentração de poder inédita dos velhos meios de comunicação. A ampliação de um ambiente discursivo coexiste com o estreitamento da variedade nas informações transmitidas pelos canais mais disponíveis. (JENKINS, 2008, p. 276)

7 "Rather than being proscribed a passive role in the political process, the electorate is symbolically or materially empowered through the two-way communication architecture to interact directly with candidates." 
Isso se reflete em todas as áreas da sociedade, inclusive nas campanhas eleitorais. Os candidatos têm usado a Internet e podem mesmo tomá-la como base para suas campanhas, mas sabem que precisam da televisão para ganhar as eleições. Enquanto na "mídia empurrada", as mensagens vão ao público sem que necessariamente este as procure, na "mídia puxada" as informações são buscadas pelo interesse do usuário. (JENKINS, 2008)

Wolton (2006) chama a atenção de que há uma contradição entre um gigante da informação e um anão da ação política, ou seja, a crescente disponibilização de informação, embora condição indispensável para o desenvolvimento democrático, não significa melhor comunicação, nem maior participação política. A comunicação exige, além de um emissor, um meio e uma mensagem, um receptor disposto e apto para ouvir, compreender e interagir. A Internet deu voz a muitos indivíduos e grupos antes "mudos socialmente", mas não pode garantir que de fato sejam ouvidos:

Hoje, saturado por todas as informações que recebe sem poder agir, o cidadão não se pode tornar um 'Apolo da informação'[...] Existe portanto uma disfunção no que respeita ao esquema da sociedade da informação. A informação não só já não cria diretamente comunicação, como também já não cria diretamente capacidade de ação. (WOLTON, 2006, p. 69)

Também numa perspectiva crítica, Kumar (2006, p. 71) avalia que a despeito da potencialidade das TIC para produzir mudanças radicais nos costumes sociais, a nova tecnologia "está sendo aplicada em uma estrutura política e econômica que confirma e reforça padrões existentes, ao invés de gerar outros." Para o autor, aqueles grupos historicamente marginalizados do acesso aos bens e serviços, excluídos da participação política e social e, portanto, alijados de sua cidadania, permanecem clientes passivos, compradores e consumidores.

Os dados empíricos da pesquisa de Gennaro e Dutton (2006), realizada com cidadãos britânicos, corroboram esse ponto de vista: as desigualdades da participação política off-line tendem a ser reproduzidas e aumentadas na participação on-line. Se na participação off-line, os 
indivíduos de grupos socioeconômicos mais baixos apresentam pouco engajamento cívico, menos da metade desses tinham engajamento em participação on-line.

A mesma pesquisa apontou que apenas um quinto dos britânicos usou a Internet para buscar informação política e, embora 92\% deles a usem como canal de comunicação, o contato com os políticos foi o menos frequente entre os usos da Internet. Os autores concluem que o potencial da internet para aumentar o engajamento político online, devido à facilidade de acesso à informação e aumento das oportunidades de comunicação, é subutilizado.

No que tange à comunicação, no entanto, deve-se relativizar a conclusão de Gennaro e Dutton (2006) porque a forma de participação política considerada - contato com políticos - limitou-se à comunicação com um ator social, quando a comunicação política pode ocorrer com outros cidadãos, organizações sociais, instituições públicas, entre outros.

Em parte concordando com Gennaro e Dutton, DiMaggio e outros (2001), baseados em pesquisas anteriores e observando o quesito informação política da perspectiva do acesso, sugerem que a Internet atua mais como um complemento para aqueles que já usavam outras fontes para manterem-se informados do que fomenta esse acesso.

Segue-se que: por um lado, a democracia encontra terreno profícuo para ser fortalecida, “[...] pelo fato de a informação ser amplamente distribuída e os fluxos de informação não poderem mais ser controlados a partir do centro", como atestam Akutso e Pinho (2002, p. 3); e por outro há outros condicionantes, como aponta Maia (2008, p. 285): “Há pouca evidência de que o acesso mais amplo às tecnologias irá, por si e sem mais, expandir o interesse pelas questões políticas simplesmente porque uma parcela maior do público tem chances de participar."

Um exemplo do referido condicionamento é o da elaboração participativa do orçamento de Belo Horizonte feita por via digital. Entre 2006 e 2008, houve um decréscimo do número de participantes de 503 mil para 113 mil. Observa-se que, no período, a Prefeitura disponibilizou canais digitais de votação para a população, com 270 pontos de votação públicos e gratuitos, e monitores treinados para auxiliar 
os cidadãos, além de um número telefônico com ligação gratuita. Isso mostra que há outros condicionantes para a participação política, como, por exemplo, motivação para engajar-se. No caso de Belo Horizonte, a queda da participação se deu na medida que, ao invés de uma dinâmica deliberativa sobre que obras realizar, o orçamento participativo era, na verdade, um plebiscito sobre obras já previamente escolhidas pela Prefeitura.

Assim como os modelos de democracia variam enormemente entre os países e regiões - abrangendo sistemas eleitorais majoritários ou proporcionais, nível de competitividade entre partidos, sistema executivo parlamentar ou presidencial etc. - mais ainda se diferem as formas de participação, a cultura política e, consequentemente, a aplicabilidade da internet para a participação social em cada uma dessas sociedades. Por exemplo, se nos Estados Unidos a Internet foi rapidamente adotada como ferramenta de lobbying e levantamento de fundos para campanhas eleitorais, esse talvez não seja o principal uso que se faz dela em campanhas nas democracias europeias ou latino-americanas.

Sampaio (2010, p. 47), que realizou uma revisão de literatura quanto à relação entre participação política e Internet, acabou por concluir que os seus usos abrem tantas possibilidades que é fácil assumir um discurso triunfalista ou apocalíptico e encontrar evidências empíricas para embasar um e outro discurso. Mas reconhece que "[...] há diversos casos que apontam incremento de valores democráticos, que só foram permitidos pelo uso da Internet." Para Ziba (2007), essa contradição acontece porque a literatura tende a focar o uso da tecnologia em si, negligenciando outros parâmetros. Para ele, a promoção da participação e inclusão através das tecnologias tem de ser um caso de ação sociotécnica, em que as influências sociais e técnicas são igualmente consideradas para promover a participação dos cidadãos. Ele verificou isso ao estudar o caso de Malawi, no qual as experiências mais bem sucedidas foram aquelas em que os atores locais tiveram autonomia para participar das escolhas tecnológicas e escolher como se daria a participação.

Inegavelmente, a Internet facilita práticas de accountability, mobilização de grupos e deliberação pública, o que incide no desenvolvimen- 
to de valores democráticos. Entretanto, a motivação para a participação política está relacionada a outros condicionantes, como a geração de efeitos reais no sistema político - o que implica em vontade política dos representantes -, confiança dos cidadãos na efetividade de sua participação e uma política que mantenha canais e oportunidades de participação abertos e contínuos.

Macintosh e Whyte (2006), a partir da avaliação de programas locais de participação política no Reino Unido, concluíram que a motivação para participar era mais importante que as ferramentas. Por outro lado, "[...] classificar a Internet como neutra é ignorar os avanços democráticos que podem ser conquistados por determinadas utilizações de diferentes ferramentas digitais, usos que não seriam possíveis sem sua presença." (SAMPAIO, 2010, p. 43) Para Gomes (2011), se genericamente tomados, os usuários da Internet não estão grandemente interessados em política, mas podem participar de modo relevante em circunstâncias específicas:

Isso me leva à ideia de que a participação online passa por questões relacionadas ao desejo tanto quanto por questões relacionadas a meios, motivos e oportunidades de participação. Se, quando assim deseja, o cidadão puder encontrar ou criar canais adequados de participação, estará, então, assegurado o princípio segundo o qual numa sociedade democrática saudável, todo concernido deve poder participar, embora nem todos concernidos sejam sempre e efetivamente participantes. O cidadão que usa intensamente tecnologias de conexão digital pode estar em estado de latência no que tange à participação e ao engajamento. (GOMES, 2011, p. 39-40, grifos do autor)

Está claro, portanto, que a literatura é farta na discussão das potencialidades e barreiras da Internet para a participação política. Como um ambiente de comunicação, é natural que ela seja também ocupada pela política como um complemento, mais uma ambientação de temas políticos. (ALMEIDA, 2010) Os estudos teóricos e empíricos consultados para a realização deste trabalho resultaram na constituição de um 
conjunto articulado de potencialidades e limitações da internet, que se mostrou altamente pertinente. Nele, o diferencial é que as unidades pesquisadas não são indivíduos, mas sim organizações que, constituídas para equacionar e resolver problemas sociais em âmbitos específicos, são levadas a desempenhar papéis de natureza política e a utilizar a internet para tal fim.

O conjunto foi organizado articulando as potencialidades e as limitações da nternet nas ações de comunicação, de informação e de procedimentos. (BORGES; JAMBEIRO, 2012) Ali se revela, entre outros aspectos: 1) que apesar de a nternet facilitar o contato e a pressão sobre os representantes eleitos, o sistema político continua fechado; 2) que embora a nternet facilite a produção e circulação de informações sem controle ou filtros do Estado, as OSC não têm produzido e feito circular muita informação de natureza política; 3) e conquanto comodidade, conforto e custo reduzido sejam tidos como incentivadores de participação, não se encontram evidências de que tenha havido incremento de participação política, em função desses fatores.

O conjunto de potencialidades e limitações da internet, que se construiu para a investigação da participação política, foi fundamental para que se pudesse fazer o estudo empírico que é apresentado a seguir. Ele não é, contudo, essencial para que se compreenda os objetivos, a metodologia e os resultados alcançados.

\section{PROCEDIMENTOS METODOLÓGICOS}

A pesquisa foi delineada para verificar as aplicações dadas às ferramentas digitais na atuação política de OSC. A amostra foi composta por organizações sediadas em Salvador, capital do Estado da Bahia, que concentra OSC atuando em frentes múltiplas de defesa de direitos civis e mediações políticas. Dada a quantidade e diversidade dessas organizações, fez-se uma seleção a partir do banco de dados do Cadastro Nacional de Entidades (CNE), do Ministério da Justiça do Brasil. A partir do Relatório Eletrônico de Prestação de Contas que cada organização disponibiliza no CNE, foram utilizados os seguintes critérios de seleção: 
I. organizações que responderam afirmativamente quanto à sua contribuição para ampliação da democracia e fortalecimento da cidadania no Questionário para Avaliação da Inserção Social;

2. organizações que tenham assento como titulares em conselhos de políticas públicas. Com a aplicação desses dois primeiros critérios, buscou-se selecionar aquelas organizações que se dispõem a ter atuação política;

3. organizações que já atuavam em 1995, ano da entrada da internet comercial no Brasil. Com esse requisito procurou-se ter acesso a informações sobre as mudanças demandadas pela inserção das TICs.

Os mesmos critérios foram aplicados na seleção do grupo em 2010 e em 2013. Com a aplicação desses critérios, chegou-se a 44 OSC em 2010 e a 32 OSC em 2013. Neste trabalho, o foco de análise são os dados mais recentes. Contudo, quando pertinente para compreender a evolução do uso da internet, os dados de 2010 são resgatados.

O instrumento de coleta de dados foi um roteiro de entrevista semiestruturada, realizada individualmente com os gestores de cada organização. A análise dos dados foi primariamente qualitativa, tendose adotado para tanto a técnica de análise de conteúdo, por meio da abordagem descritiva, correlacional e interpretativa. Contudo, análises quantitativas foram adotadas, como complementares, visando à representação dos dados por meio de gráficos, quadros e tabelas.

$\mathrm{Na}$ discussão dos resultados, a seguir, algumas falas dos entrevistados são apresentadas, a título ilustrativo dos dados obtidos. Para destacá-las, usou-se o itálico em sua apresentação.

\section{PARTICIPAÇÃO POLÍTICA E INTERNET: ANÁLISE DAS INFORMAÇÕES} EMPÍRICAS

Nesta parte do trabalho, serão apresentados os resultados que constituem sua contribuição original e que são fruto da interpretação dos dados obtidos na pesquisa de campo, levando em conta o referencial teórico construído previamente. 


\section{Caracterização das organizações}

Antes de se tratar da atuação política das organizações, é preciso registrar que nenhuma foi criada com fins políticos. Todas surgem com objetivos específicos de natureza social, que se mantêm ao longo do tempo. Para evidenciar isso, buscou-se uma generalização - embora todas as organizações atuem em mais de uma causa - na qual foram classificadas de acordo com seus objetivos iniciais (Quadro 1).

Quadro 1 - Classificação por área de atuação inicial das organizações

\begin{tabular}{|c|c|c|}
\hline QUANT. & CATEGORIAS & NOME DA ORGANIZAÇÃO \\
\hline 8 & $\begin{array}{l}\text { DEF } \\
\text { Organizações que } \\
\text { direcionam esforços para } \\
\text { defesa de direitos e inclusão } \\
\text { social de pessoas portadoras } \\
\text { de algum tipo de deficiência } \\
\text { física ou mental }\end{array}$ & $\begin{array}{l}\text { Associação de Pais e Amigos Excepcionais } \\
\text { de Salvador (Apae) } \\
\text { Associação Bahiana de Recuperação do } \\
\text { Excepcional (Abre) } \\
\text { Associação Baiana de Deficientes Físicos } \\
\text { (Abadef) } \\
\text { Associação de Pais e Amigos de Crianças } \\
\text { e Adolescentes com Distúrbios de } \\
\text { Comportamento } \\
\text { Associação de Pais e Amigos de Deficientes } \\
\text { Auditivos do Estado da Bahia (Apada) } \\
\text { Instituto de Organização Neurológica da } \\
\text { Bahia (lonba) } \\
\text { Instituto Guanabara } \\
\text { Instituto de Cegos da Bahia }\end{array}$ \\
\hline 8 & $\begin{array}{l}\text { COM } \\
\text { Instituições que atuam } \\
\text { em causas relacionadas à } \\
\text { organização e fortalecimento } \\
\text { de comunidades }\end{array}$ & $\begin{array}{l}\text { Associação Beneficente e Recreativa } 28 \text { de } \\
\text { setembro } \\
\text { Associação das Comunidades Paroquiais de } \\
\text { Mata Escura e Calabetão (Acopamec) } \\
\text { Clube de Mães do Bairro de Pernambués } \\
\text { Coordenadoria Ecumênica de Serviço (Cese) } \\
\text { Fundação Odebrecht } \\
\text { Associação de Moradores do Conjunto } \\
\text { Santa Luzia } \\
\text { Voluntárias Sociais da Bahia } \\
\text { Associação Centro Social Fraternidade } \\
\text { Bahiana }\end{array}$ \\
\hline
\end{tabular}




\begin{tabular}{|c|c|c|}
\hline 6 & $\begin{array}{l}\text { REL } \\
\text { Organizações ligadas a } \\
\text { ordens católicas ou centros } \\
\text { espíritas }\end{array}$ & $\begin{array}{l}\text { Centro Espírita Celeiro de Paz } \\
\text { Centro Espírita Deus, Luz e Verdade } \\
\text { Federação Espírita do Estado da Bahia } \\
\text { (Feeb) } \\
\text { Fundação Lar Harmonia } \\
\text { Instituto Social das Medianeiras da Paz } \\
\text { Fundação Instituto São Geraldo }\end{array}$ \\
\hline 5 & $\begin{array}{l}\text { EDU } \\
\text { Organizações que } \\
\text { começaram suas atividades } \\
\text { voltadas para a educação }\end{array}$ & $\begin{array}{l}\text { Associação e Centro de Educação Maria } \\
\text { Dolores } \\
\text { Instituto Nossa Senhora da Salette } \\
\text { Associação Universitária e Cultural da Bahia } \\
\text { Casa Pia Colégio dos Órfãos de São Joaquim } \\
\text { Colégio do Sagrado Coração de Jesus }\end{array}$ \\
\hline 2 & $\begin{array}{l}\text { ABR } \\
\text { Organizações que têm como } \\
\text { ação prioritária o abrigo de } \\
\text { menores ou idosos }\end{array}$ & $\begin{array}{l}\text { Fraternidade Nossa Senhora da Piedade } \\
\text { (Abrigo Mariana Magalhães) } \\
\text { Casa de Santa Maria }\end{array}$ \\
\hline 2 & $\begin{array}{l}\text { SAU } \\
\text { Organizações que podem ser } \\
\text { enquadradas entre aquelas } \\
\text { que prestam prioritariamente } \\
\text { serviço de promoção e } \\
\text { proteção da saúde }\end{array}$ & $\begin{array}{l}\text { Grupo de Apoio à Criança com Câncer de } \\
\text { Salvador (Gacc) } \\
\text { Núcleo de Apoio ao Combate do Câncer } \\
\text { Infantil (Nacci) }\end{array}$ \\
\hline 1 & $\begin{array}{l}\text { AMB } \\
\text { Organizações que têm como } \\
\text { foco questões relacionadas } \\
\text { ao meio ambiente }\end{array}$ & Instituto de Permacultura da Bahia \\
\hline
\end{tabular}

Fonte: Pesquisa dos autores, 2013.

Como se pode verificar, elas são bastante heterogêneas, o que as leva a ter metas diversas, a partir de motivações diferentes, escolherem linhas de ação específicas, nem sempre compartilhando os mesmos valores, além de terem visões por vezes conflituosas dos demais atores sociais - principalmente do poder público - e do seu próprio papel político.

Essa classificação generalista estabelece sete grandes categorias de áreas de atuação, entre as quais a participação política não aparece. No entanto, a despeito de manterem seus objetivos fundacionais, essa 
participação posteriormente se impõe como uma atividade essencial para atingir os objetivos "não políticos", conforme transparece na fala:

A gente vai [aos conselhos de políticas públicas] para representar a população. Trazemos as informações desses espaços para a comunidade e levamos os problemas da comunidade para lá também. Assim, esses fóruns contribuem de forma substancial para o desenvolvimento de nossas atividades (REL)

Vale ressaltar, no entanto que, embora em menor número, há organizações que reconhecem que a política está na raiz de sua atuação:

A todo instante fazemos política. Não existem ações nesse nivel que não tenham o cunho político. A política é inerente a essas ações. Se a gente interage com a sociedade, interage com o poder público, interage com os associados, a gente está fazendo política a todo instante. (DEF)

\section{A aplicação da internet na atuação política}

A partir de levantamento realizado por pesquisa anterior (BORGES, 2013), foram propostas 21 formas de participação política às organizações. Todas as formas são praticadas por, pelo menos, uma das organizações, embora filiação e promoção de partido político tenham sido assinaladas por apenas uma. Por isso, essas formas de participação foram excluídas desta parte do estudo, em função de sua baixa relevância frente às demais.

Duas organizações disseram não utilizar a internet em nenhuma das formas de participação política. Com isso, a pesquisa nesta etapa apresenta dados de 30 organizações que, em graus e formas diferentes, relacionaram a internet como ferramenta para levar a cabo a atuação política a que se propõem. O Gráfico 1 ilustra o peso relativo da internet para cada uma das formas de participação. 
Gráfico 1 - O peso da internet na participação política em 2013

- OSC que atuam na forma de participação

- OSC que usam a internet na forma de participaçăo

- Percentual da correlaçăo entre a atuaçăo política e o uso da internet

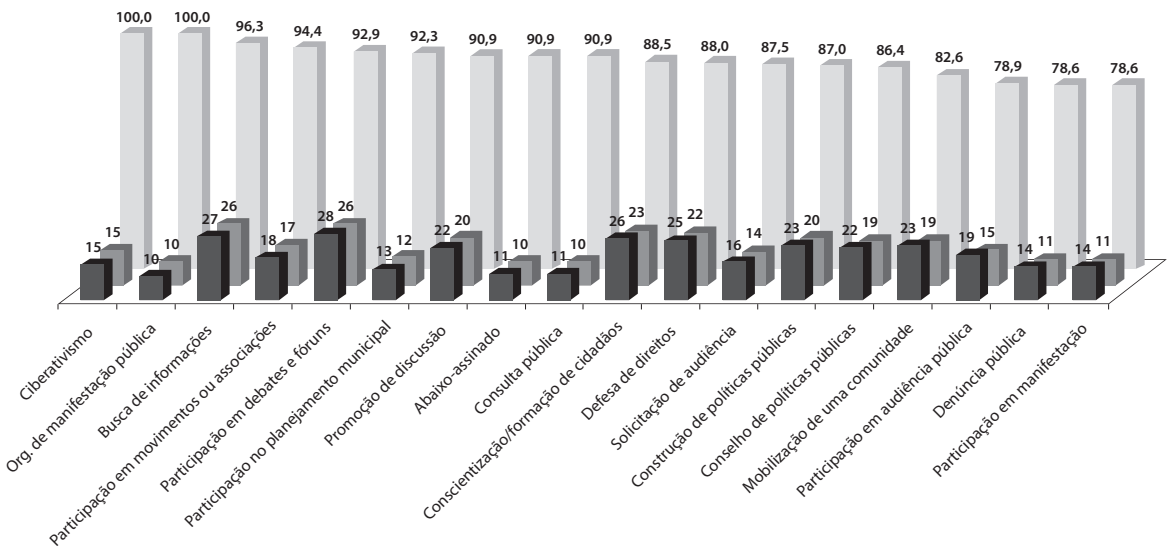

Fonte: Pesquisa dos autores, 2013.

O resultado mais relevante é a constatação do expressivo uso da internet em todas as formas de participação política. Essa é uma informação que difere fortemente da realidade levantada em 2010 (Gráfico 2).

No levantamento realizado em 2010, a internet apresentava-se mais presente no ciberativismo, assim como na busca por informações e na comunicação engendrada para a construção de políticas públicas. Nas demais formas de atuação política, a correlação caía para menos de $60 \%$. Atualmente, além dos recursos digitais serem utilizados em todas as ações, a menor correlação é de 78,6\%, o que demonstra a imprescindibilidade e crescente convergência entre os recursos digitais de informação e comunicação e a participação política praticada pelas organizações. 
Gráfico 2 - O peso da internet na participação política em 2010

- OSC que atuam na forma de participaçăo

-1. OSC que usam a internet na forma de participaçăo

Percentual da correlaçăo entre a atuação política e o uso da internet

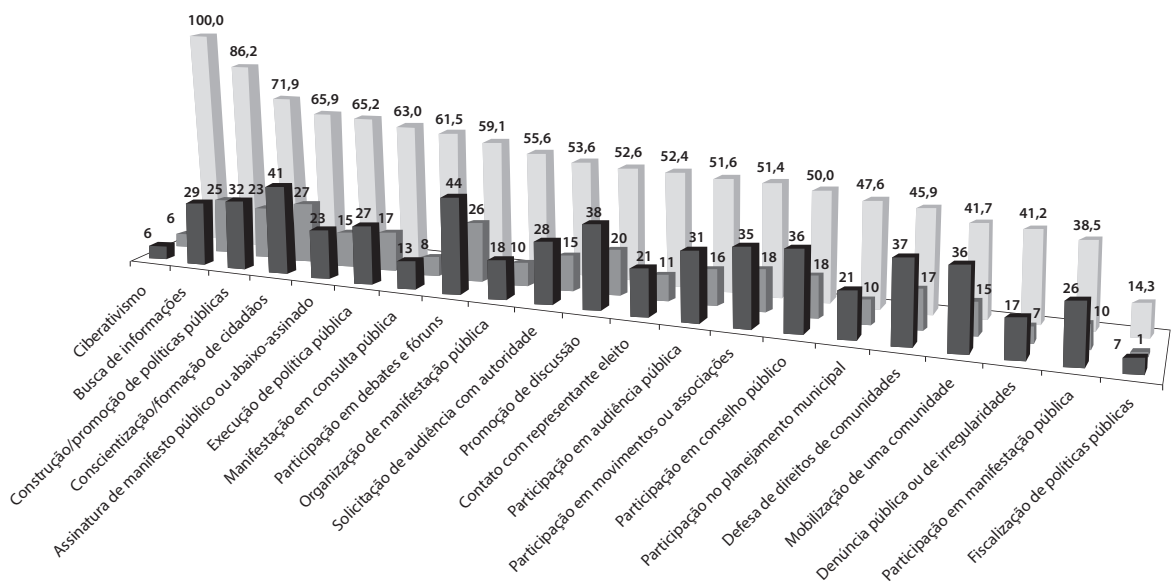

Fonte: Pesquisa dos autores, 2010

Quinze organizações disseram praticar ciberativismo, que é uma atividade relacionada ao uso de meios eletrônicos para organizar e mobilizar as pessoas em torno de uma causa. Ainda que seja discutível se de fato metade das organizações se valha dos recursos tenológicos com esse fim, já que muitas têm sítios eletrônicos com aspecto meramente informativo de suas ações, deve-se considerar o fato de que muitas delas estão diversificando as ferramentas que mobilizam para esse fim: das 30, nove mantêm blogs e 15 estão em redes sociais online. Também aparecem, porém com menos intensidade, mecanismos como chats, teleconferências e aplicativos como o Skype. A pesquisa de Pereira (2011, p. 14) encontrou indicadores semelhantes:

A Internet pode colaborar com o processo de mobilização através de boletins, e-mails, listas de discussão, blogs, twitters e sites. As redes telemáticas se baseiam principalmente em práticas descentralizadas entre as entidades, suas bases e os militantes internautas ocasionais, através da construção de um espaço cooperativo que oferece informações vindas das mais variadas fontes e que pode vir a enriquecer as práticas coletivas. 
No levantamento realizado em 2010, apenas 55,6\% das OSC que organizavam manifestações, utilizavam a internet de alguma forma. Atualmente, observa-se que todas se valem da plataforma como meio para mobilizar grupos em torno das manifestações. Na cauda de organizações ao redor do mundo que vêm empregando a internet - e, em especial, as redes digitais - para mobilizar para manifestações, todas as 10 organizações que atuam nessa forma de participação política, utilizam os recursos digitais para tal fim. No momento do levantamento de dados para este trabalho (junho de 2013), aconteciam manifestações em todo o Brasil que reuniam, em um único dia, somando-se os participantes de todas elas, mais de um milhão de pessoas. Essa grandiosidade e capilaridade das ações só foi possível pela apropriação das redes sociais online: não há um centro organizador das ações, há sim uma diversidade de movimentos sociais, grupos e também cidadãos não ligados a eles que tomam conhecimento da situação, divulgam informações e se mobilizam espontaneamente a partir das redes. Características da internet como baixo custo, rápida disseminação da informação e amplo alcance a tornaram uma ferramenta poderosa para mobilizar, organizar e maximizar a atuação dessas organizações:

[...] o poder integrador das páginas web e do universo que formavam trouxe para a comunicação distribuída a reunião dos diferentes movimentos em ações coletivas, seja para empreender uma luta comum, seja para construir uma atividade comum. [...] Nasce a guerra em rede (netwar), que permite aos movimentos sociais lutarem vantajosamente contra Estados e corporações. O movimento zapatista, nascido em 1994, será o principal exemplo desse poder e a principal escola de aprendizado para ONG e movimentos sociais. (ANTOUN, 2008, p. 16)

Como fontes de informação, os canais disponibilizados na internet tornaram-se os preferidos por quase todas as organizações. A proximidade entre informação e participação política fica evidenciada ao se constatar que 26 das 27 organizações que reconhecem essa relação, valem-se da internet como plataforma de acesso. Para além do acesso, no 
entanto, vale destacar outro uso da Internet pelas OSC que é a contribuição que têm dado na gestão e disseminação de informação política para públicos com determinado recorte de interesse. Como alguns autores (BOBBIO, 1997; MAIA, 2008) vêm reportando, é improvável que todos os cidadãos tenham um interesse ativo em participar de todos os assuntos públicos, então pode ser de grande valia encontrar esses assuntos minimamente organizados e com linhas de ação projetadas quando e para os que se interessam.

Os movimentos sociais têm como importante diretiva de ação a reapropriação dos códigos para remeter à realidade. Para isso, recorrem à produção e publicização de informação e/ou contra-informação, de modo a potencializar sua ação política, fato que pode ser notado na presença de inúmeros websites dedicados a campanhas globais de caráter ambientalista, humanista, pacifista ou econômico. (REIS, MARTINS, 2009)

Por outro lado, a internet possibilita uma individualização das informações acessadas, à medida que as pessoas podem selecionar somente os pontos de vista convergentes com os seus, o que enfraquece os ideais republicanos de exposição do cidadão a múltiplas facetas e motivações. (EISENBERG, 2003) Além disso, com a profusão do uso de redes sociais online, as informações passam a circular restritamente, fora dos padrões abertos que deram origem à web. Ou seja, o acesso à informação nessas redes sociais depende de login e "aceite" do outro, levando ao cerceamento do compartilhamento de conteúdo, o que vai contra o próprio princípio da internet de livre circulação:

A se continuar a existência de uma passividade acrítica na Web, criadores/usuários poderão ficar cada vez mais dependentes de plataformas e recursos dispostos em 'ilhas', sem a mesma ubiquidade promovida nos primórdios da internet e da Web. (VILARIM, 2013)

Embora a participação em movimentos ou associações não esteja entre as principais formas de participação política assim consideradas pelas organizações (18 delas), é visível seu interesse (17) em manter articulações, seja com outras congêneres, seja com aquelas do seu en- 
torno, via recursos digitais. As principais justificativas para o emprego da tecnologia estão na facilidade e economia para encontrar e manter a comunicação com pares, utilizando ferramentas e aplicativos como chats, WhatsApp e correio eletrônico, este, ainda, o mais utilizado. O depoimento é ilustrativo das afirmações:

A [organização] tem um papel de intermediar temas polêmicos como o movimento gay, o movimento negro[...] a igreja não apoia o aborto, o movimento feminista apoia, às vezes recebemos críticas pesadas, mas mentemos a nossa posição de intermediar e promover o diálogo entre as diferenças. [...] A internet viabilizou uma maior atuação no panorama nacional e internacional, podemos publicar mais para fora, por exemplo no caso dos quilomboas tivemos resposta de outros países. (COM)

Há também um aspecto relacionado a uma conjuntura local: com o Brasil ocupando a terceira posição entre os países em usuários do Facebook e a necessidade premente das OSC de estreitar laços com parceiros, colaboradores e sociedade civil para manterem-se competitivas, apresenta-se uma convergência entre um contexto cultural que valoriza a participação em redes sociais on-line - o que impulsiona as organizações para esse ambiente que, por sua vez, facilita enormemente a divulgação de ações e o compartilhamento de experiências e vivências - e os objetivos institucionais que reclamam visibilidade e aceitação social.

Com relação aos demais usos políticos, as organizações vão experimentando os recursos tecnológicos como aliados para divulgar e buscar apoio para suas causas, para abrir espaços de discussão e também na tentativa de mobilizar as pessoas para participar de ações, tanto no mundo virtual como no real. Portanto, tendem a usar ações híbridas - ações on-line e off-line - para aumentar o alcance de suas propostas:

A [organização] sempre foi avançada no uso da tecnologia. Estamos muito on-line, melhorando a nossa linguagem para atingir o público de uma forma geral, principalmente por causa da captação de recursos, inclusive com as redes sociais, com estratégias de mobilização que nós usamos para advogar os direitos das organizações que a gente apoia. (COM) 
Em suma, o emprego da internet no contexto da atuação política de organizações da sociedade civil, está intimamente relacionado à comunicação, obtenção e/ou busca de informação e visibilidade dos serviços e ações políticas desenvolvidas. Nesta pesquisa, contudo, foram observados empregos mais específicos, explicitados na emergência do uso de redes sociais eletrônicas, na prestação de contas nos websites e na utilização da internet para a captação de recursos.

Junto ao desenvolvimento das tecnologias e recursos informacionais e comunicacionais está a tendente migração das atividades humanas para os espaços digitais que compõem o ciberespaço. As organizações da sociedade civil parecem ter visto nesta tendência uma oportunidade de potencializar sua atuação política e social perante esta sociedade mais conectada à internet.

\section{CONCLUSÃO}

Os resultados permitem concluir que a internet por si só não impulsiona a participação política, visto que atua de forma complementar, mas potencializa a atuação já efetivada pelas OSC. Isto se coaduna com as conclusões de Norris (2001) em suas pesquisas com amostras de grupos sociais nos Estados Unidos e na Europa, nas quais observou que a internet não mobilizava grupos inativos, mas reforçava as tendências pré-existentes em participação política.

Em qualquer caso, a apropriação da internet pelas organizações de sociedade civil pode ser entendida como a incorporação de uma nova plataforma tecnológica que vai além de uma mera ferramenta: a internet tem representado um ambiente de informação diversificada e comunicação distribuída, uma alternativa relevante à informação massificada e à comunicação unilateral. Ela estabelece para as OSC um locus adequado ao fortalecimento da participação política.

Merece destaque a ênfase que as ferramentas digitais ganharam na atuação das organizações quando se comparam os dados levantados em 2010 e em 2013. Em três anos, essas ferramentas saíram da posição de "opção" para se tornarem uma necessidade quando se fala em acesso à informação e comunicação para as OSC. Vinte e sete de- 
las $(84,4 \%)$ indicaram a busca de informação entre as atividades que empreendem a fim de participarem dos processos sociais. Trata-se de uma vinculação presente nos modelos teóricos da democracia, e que nesta pesquisa encontrou reflexo nos dados empíricos, ou seja, está muito presente no discurso das OSC o entendimento de que precisam estar bem informadas para compreender a sociedade e buscar soluções para seus problemas. Da mesma forma, há a compreensão de que nos espaços públicos de que participam, precisam fazer intervenções com base na leitura do cenário e, portanto, mais uma vez, munidas de informações seguras, abrangentes e relevantes.

Percebe-se que a participação política torna-se cada vez mais híbrida, uma vez que utilizando os espaços on-line e off-line, as OSC integram várias mídias para interagir com a sociedade. A capacidade de mobilizar os recursos da internet para estabelecer e manter comunicação, conseguir cooperação e organizar manifestações é, portanto, um diferencial na atuação política recente das OSC. Contudo, não há indícios de que a internet por si só impulsionou a participação política: está mais do que claro que ela atua de forma a complementar a motivação política já existente na organização, isto é, ela é uma ferramenta que potencializa as ações desenvolvidas pelas organizações da sociedade civil.

\section{REFERÊNCIAS}

AKUTSU, L.; PINHO, J. A. G. Sociedade da informação, accountability e democracia delegativa: investigação em portais de governo no Brasil. RAP, v. 36, n. 5, set./out. 2002.

ALMEIDA, G. W. D. Participação política e democracia no Brasil. In: CONGRESSO BRASILEIRO DE CIÊNCIAS DA COMUNICAÇÃO, 33., 2010, Caxias do Sul. Anais... São Paulo: Sociedade Brasileira de Estudos Interdisciplinares da Comunicação, 2010. Disponível em:<http://www. intercom.org.br/papers/nacionais/2010/resumos/R5-1192-1.pdf>. Acesso em: 2 out. 2011.

ANTOUN, H. De uma teia à outra: a explosão do comum e o surgimento da vigilância participativa. In: ANTOUN, H. (Org.). Web 2.o: participação 
e vigilância na era da comunicação distribuída. Rio de Janeiro: Mauad X, 2008. p. 11-28.

BOBBIO, N. O futuro da democracia: uma defesa das regras do jogo. 6. ed. Rio de Janeiro: Paz e Terra, 1997.

BORGES, J. O uso da internet por organizações da sociedade civil enquanto atores cívicos. Revista Fronteiras, São Leopoldo, v. 14, n. 2 , p. 121-132, maio/ago. 2012. Disponível em: < http://revistas.unisinos.br/ index.php/fronteiras/article/view/fem.2012.142.06/997>

BORGES, J. Participação política, internet e competências infocomunicacionais: evidências a partir de organizações da sociedade civil de Salvador. Salvador: Edufba, 2013.

BORGES, J. et al. Competências infocomunicacionais: um conceito em desenvolvimento. Tendências da Pesquisa Brasileira em Ciência da Informação, v. 5, p. 10, 2013.

BORGES, J.; BRANDÃO, G.; MARTINS, G. Competências em comunicação: observação em organizações da sociedade ciivil de Salvador. Revista Comunicando, v. 2, p. 320-333, 2013.

BORGES, J.; JAMBEIRO, O. A internet na participação política de organizações da sociedade civil. In: PINHO, J. A. G. (Org.). Estado, sociedade e interações digitais: expectativas democráticas. Salvador: Edufba, 2012a. p. 41-62.

BORGES, J.; JAMBEIRO, O. Participação política de organizações da sociedade civil de Salvador. Verso e Reverso, v. 26, n. 61, p. 2-14, jan./ abr. 2012b. Disponível em: <http://revistas.unisinos.br/index.php/ versoereverso/article/viewFile/ver.2012.26.61.01/732>.

BORGES, J.; LESSA, B. ; BRANDÃO, G. Apropriação da internet na atuação política de organizações da sociedade civil de Salvador. Redes. com - Revista de Estudios para el Desarrollo Social de la Comunicación, v. 8, p. 107-129, 2013.

BUCY, E.; GREGSON, K. Media participation: a legitimizing mechanism of mass democracy. New Media at Society, v. 3, n. 3, p. 357-380, 2001.

CHRISSAFIS, T.; ROHEN, M. European eParticipation developments. JeDEM, v. 2, n. 2, p. 89-98, 2009 . 
DIMAGGIO, P. et al. Social implications of the Internet. Annual Review of Sociology, v. 27, p. 307-336, 2001.

EISENBERG, J. Internet, Democracia e República. Revista de Ciências Sociais, Rio de Janeiro, v. 46, n. 3, p. 491-511, 2003.

GENNARO, C. D.; DUTTON, W. The Internet and the public: online and offline political participation in the United Kingdom. Parliamentary Affairs, v. 59, n. 2, p. 299-313, 2006.

GEPICC. Grupo de Estudos de Políticas de Informação, Comunicações e Conhecimento. Salvador: UFBA, 2013. Disponível em: <http://www. gepicc.ufba.br/>.

GOMES, W. A democracia digital e o problema da participação civil na decisão política. Revista Fronteiras, São Leopoldo, v. 7, n. 3, p. 214-222, set./dez. 2005 a.

GOMES, W. Participação política online: questões e hipóteses de trabalho. In: MAIA, R. C. M. et al. (Org.). Internet e participação política no Brasil. Porto Alegre: Sulina, 2011. Cap.1. p. 19-45. (Cibercultura).

JAMBEIRO, O.; BORGES, J. Internet, participação política e organizações da sociedade civil. Revista Eco-Pós, Rio de Janeiro, v. 13, p. 124-145, 2010. Disponível em: < https://revistas.ufrj.br/index.php/ eco_pos/article/view/889>.

JENKINS, H. Cultura da convergência. São Paulo: Aleph, 2008.

JOHNSTON, P. Transforming government's policy-making processes. JeDEM, v. 2, n. 2, p. 162-169, 2009.

KUMAR, K. A Sociedade de Informação. In: KUMAR, K. (Org.). Da sociedade pós-Industrial à pós-moderna: novas teorias sobre o mundo contemporãneo. Rio de Janeiro: Jorge Zahar, 2006. p. 45-74.

MACINTOSH, A.; WHYTE, A. Evaluating how eparticipation changes local democracy. In: EGOBERNMENT WORKSHOP'o6 (EGOVo6), 6., 2006 , West London. Anais... London: Brunel University, 2006. Disponível em:<http://www.iseing.org/egov/eGOVo6/Accepted\%20 Papers/624/CRC/Evaluation\%2oof\%2oeParticipationv-v2-submitted. pdf>. Acesso em: 2 out. 2011. 
MAIA, R. Redes cívicas e internet: efeitos democráticos do associativismo. In: GOMES, W; MAIA, R. C. M. (Org.). Comunicação e democracia: problemas \& perspectivas. São Paulo: Paulus, 2008. p. 327-348.

MAIA, R. Internet e esfera civil: limites e alcances da participação política. In: MAIA, R. C. M. et al. (Org.). Internet e participação política no Brasil. Porto Alegre: Sulina, 2011. Cap.2. p. 47-91.

NUNES, M. V. Novas tecnologias e cidadania: a internet como fator de politização ou de adequação das comunidades excluídas ao sistema produtivo? In: CONGRESSO BRASILEIRO DE CIÊNCIAS DA COMUNICAÇÃO, 30., 2007, Santos. Anais... São Paulo: Sociedade Brasileira de Estudos Interdisciplinares da Comunicação, 2007. Disponível em:<http://www.intercom.org.br/papers/nacionais/2007/ resumos/Ro113-1.pdf>. Acesso em: 2 out. 2011.

PEREIRA, M. A. Internet e mobilização política: os movimentos sociais na era digital. In: ENCONTRO DA COMPOLÍTICA, 4, 2011, Rio de Janeiro. Anais... Rio de Janeiro: Associação Brasileira de Pesquisadores em Comunicação e Política, 2011. Disponível em:<http://www. compolitica.org/home/wp-content/uploads/2011/03/Marcus-Abilio. pdf>. Acesso em: 2 out. 2011.

REIS, A. S.; MARTINS, A. A. L. Movimentos sociais, informação e mediação: uma visão dialética das negociações de sentido e poder. DataGramaZero - Revista de Ciência da Informação, Rio de Janeiro, v. 10, n. 5, out. 2009. Disponível em:<http://www.dgz.org.br/outo9/Art_04. htm>. Acesso em: 27 set. 2011.

RONCA, A. C. C.; COSTA, R. A construção de uma democracia cognitiva. São Paulo em Perspectiva, v. 16, n. 4, p. 24-29, 2002.

SAMPAIO, R. Participação política e os potenciais democráticos da internet. Revista Debates, v. 4, n. 1, p. 29-53, jan./jun. 2010.

SANTOS, B. Democratizar a democracia: os caminhos da democracia participativa. Rio de Janeiro: Civilização Brasileira, 2002.

VILARIM, G. de O. Produção de conhecimento na web e passividade acrítica nas novas plataformas de software. In: ENCONTRO NACIONAL DE PESQIOSA E, CIÊNCIA DA INFORMAÇÃO, 13., Florianópolis. Anais... Florianópolis: Ancib, 2013. 
WOLTON, D. É preciso salvar a comunicação. Casal de Cambra: Caleidoscópio, 2006.

ZIBA, A. Technology choices and 'literacies' for eParticipation in Malawi. In: AVDIC, A. et al. (Org.). Understanding e Participation:

Contemporary PhD eParticipation Research in Europe. Örebro: Örebro University Library, 2007. p. 167-182. 